\title{
Geosciences after Paris
}

\author{
Joeri Rogelj and Reto Knutti
}

\section{The adoption of the Paris Agreement is a historic milestone for the global response to the threat of climate change. Scientists are now being challenged to investigate a $1.5^{\circ} \mathrm{C}$ world - which will require an accelerated effort from the geoscience community.}

G avel down. Standing ovation. Smiles and congratulating handshakes. The Paris Agreement has been adopted ${ }^{1}$. The world has entered a new political era in the global reaction to climate change. The way forward can now be found in the 12 pages of the Paris Agreement.

This agreement aims at holding "the increase in the global average temperature to well below $2{ }^{\circ} \mathrm{C}$ above pre-industrial levels and to pursue efforts to limit the temperature increase to $1.5^{\circ} \mathrm{C}$ above pre-industrial levels". It also recognizes "that this would significantly reduce the risks and impacts of climate change". But in what way the risks and impacts for $1.5^{\circ} \mathrm{C}$ differ from those for $2{ }^{\circ} \mathrm{C}$ or $2.5^{\circ} \mathrm{C}$ is unclear and requires further investigation by the geoscience community, which can then contribute to the climate policy discussions.

Since the inception of the United Nations Framework Convention on Climate Change (UNFCCC) in 1992, governments have been working with the objective of preventing "anthropogenic interference with the climate system"2. Since the 2009 UNFCCC negotiations in Copenhagen, and in particular during the following years, the translation of this broad objective became progressively more specific, first with a mention of a $2{ }^{\circ} \mathrm{C}$ limit, and now with a clear recognition that the warming is to be held to well below $2{ }^{\circ} \mathrm{C}$, and potentially even $1.5^{\circ} \mathrm{C}$. These much more specific global climate targets come with consequences, and the geosciences, even more so than in the past, will play a key role in mapping out and quantifying these.

\section{Recovery from overshoot}

The question of how warming can be limited to below $2{ }^{\circ} \mathrm{C}$ has been extensively investigated by the scientific community, but the question of how to return longterm warming to below $1.5^{\circ} \mathrm{C}$ has received much less attention. Given current best knowledge of the climate response to greenhouse gas emissions, it will be very hard - if not impossible - to keep warming to below $1.5^{\circ} \mathrm{C}$ during the entire twenty-first century ${ }^{3}$. Even when emissions are reduced at very high rates in the coming decades, we might well have to deal with a temperature overshoot.

In principle, such behaviour of our geophysical system is possible but the details about tipping points and reversibility of impacts are unknown. There is a rich literature available on warming under increasing or stabilizing atmospheric greenhouse gas concentrations, as well as on peak warming and its relation to cumulative emissions of carbon ${ }^{4}$. This literature needs to be extended, to deepen our understanding about the rate and possible limits of returning warming to significantly lower levels after a temperature overshoot. The Paris Agreement does not provide a time frame for achieving $1.5^{\circ} \mathrm{C}$, most likely because none could be agreed upon. When tackling this question, the various processes at play should therefore be explored for limiting warming to $1.5^{\circ} \mathrm{C}$ both before the end of this century and beyond.

\section{Negative emissions}

For warming to peak and decline, carbon dioxide will have to be actively removed from the atmosphere. At present, this remains an unsolved challenge on a global scale. Removal of carbon dioxide can be achieved through a variety of processes, including afforestation, forest management, the combination of bioenergy with carbon capture and storage $\mathrm{e}^{5}$, or through dedicated activities, for example, direct air capture and sequestration, and enhanced weathering of olivine rocks ${ }^{6}$. The pace at which such negative emissions options can scale up is a key unknown, and ultimately lies more in the social sciences or in the field of technology and engineering.

Important questions are, however, left to be answered by the geosciences, too. We need to understand, for example, potential geophysical limits of the magnitude of such negative emissions and safe storage capacity $^{7}$, the behaviour of the carbon cycle under rapidly decreasing concentrations at higher temperatures (including the presence of tipping points or non-linearities like $\mathrm{CO}_{2}$ emissions from permafrost), as well as the implications of the required land-use changes on local climate and the global radiative balance. Further concerns involve the possible consequences for forests, water use and availability of nutrients, and the identification of risks of possible adverse side effects. Research on negative emissions provides the geoscience community with a renewed opportunity to reach out to other communities and foster an integrated understanding of this issue.

\section{Non- $\mathrm{CO}_{2}$ contributions}

Stabilizing global mean temperatures requires global carbon dioxide emissions to become virtually zero ${ }^{8,9}$. The Paris Agreement goes even further. In its fourth article, it spells out that one of its aims is "to achieve a balance between anthropogenic emissions by sources and removals by sinks of greenhouse gases in the second half of this century"'. Some sources of non- $\mathrm{CO}_{2}$ greenhouse gas emissions are still notoriously difficult to mitigate, particularly in the agricultural sector. Bar breakthroughs in non- $\mathrm{CO}_{2}$ mitigation technologies beyond our current imagination, achieving such a balance will thus involve net negative $\mathrm{CO}_{2}$ emissions that compensate any residual non- $\mathrm{CO}_{2}$ greenhouse gas emissions. Metrics and definitions to determine what such a 'balance of greenhouse gases' means vary, are uncertain ${ }^{10}$ and can lead to different climate impacts. Also here, the geosciences can improve our understanding and inform the debate in the coming years at both a conceptual and a practical level.

Once $\mathrm{CO}_{2}$ emissions approach nearzero levels, non- $\mathrm{CO}_{2}$ forcers become the dominant knob to control peak warming. This includes all anthropogenic non- $\mathrm{CO}_{2}$ forcers, including black carbon and sulfur dioxide, not just the non- $\mathrm{CO}_{2}$ greenhouse gases like methane, nitrous oxide, and halocarbons that are included in the Paris Agreement. Thus, effective reductions in non- $\mathrm{CO}_{2}$ forcing at the time of achieving global net zero carbon emissions could 

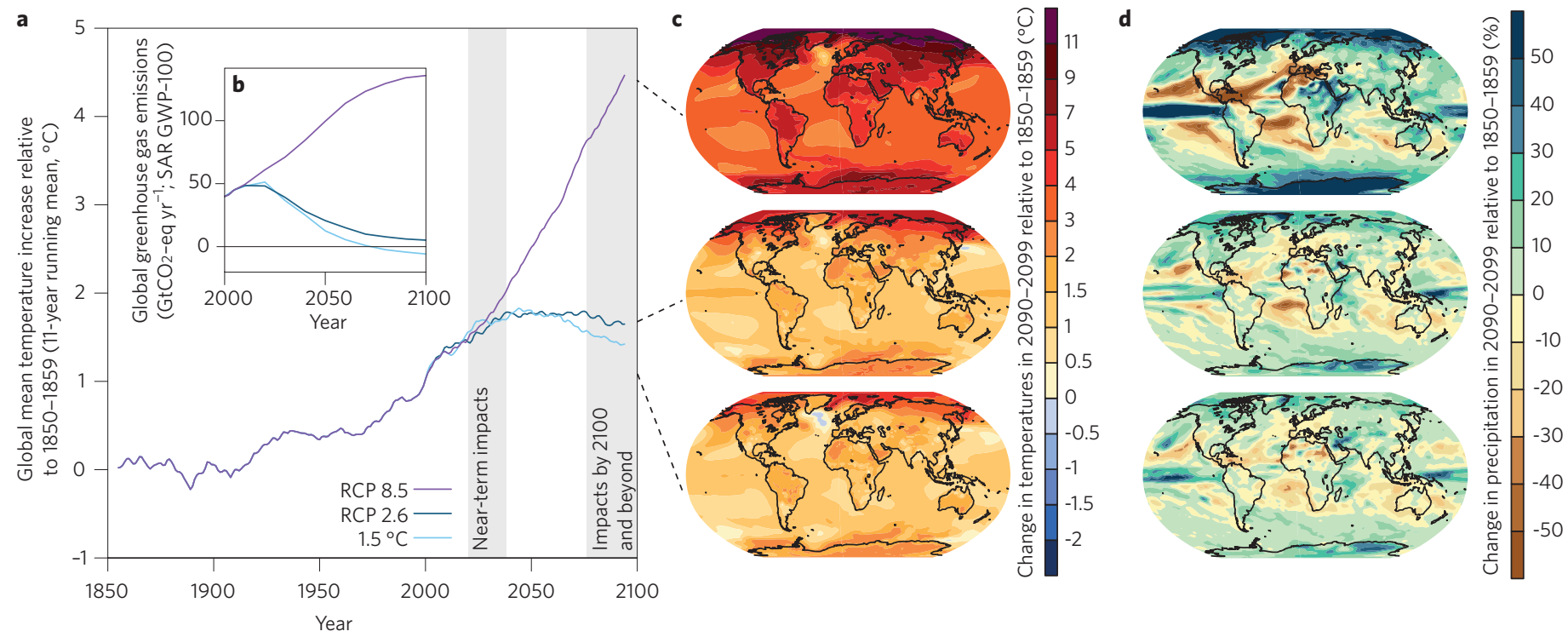

Figure 1| Geoscience research challenges related to the UNFCCC Paris Agreement. a,b, In order to investigate a $1.5^{\circ} \mathrm{C}$ world, climate modellers will need to analyse emission scenarios, such as the one depicted, which initiate stringent mitigation in 2020 and return warming to below $1.5^{\circ} \mathrm{C}$ before 2100 (light blue lines in panels $\mathbf{a}$ and $\mathbf{b}$, from ref. 13, simulated with the fully coupled Community Earth System Model ${ }^{14}$ ), in addition to the widely used Representative Concentration Pathways (RCP 8.5 and RCP 2.6). Greenhouse gas emissions in panel b are aggregated with the 100-year global warming potential metric (GWP-100) reported in the IPCC Second Assessment Report (SAR). c,d, The differences in end-of-century temperature (c) and precipitation (d) change relative to pre-industrial levels between the high-end scenario (RCP 8.5) and the two lower-end options (RCP 2.6 and $\left.1.5^{\circ} \mathrm{C}\right)$ are - expectedly - much more pronounced than those between a 1.5 and a below $2{ }^{\circ} \mathrm{C}$ world, and differ depending on the time horizon. The effect of an additional half degree can nevertheless significantly change risk assessments of extreme events, long-term sea-level rise or low-probability high-impact outcomes, to name a few. These effects, together with challenges of the corresponding emission pathways, require more detailed investigations.

additionally contribute to achieving the Paris Agreement's objective of holding temperature rise to "well below $2{ }^{\circ} \mathrm{C}$ ". However, the climate response to some non- $\mathrm{CO}_{2}$ forcers, particularly the response to short-lived climate pollutants like black carbon ${ }^{10}$, is much more uncertain than the response to $\mathrm{CO}_{2}$. Furthering understanding of the impact of non- $\mathrm{CO}_{2}$ forcers can hence help with reducing the uncertainty surrounding peak warming. Importantly, this again provides the geosciences with an excellent opportunity for interdisciplinary collaboration.

\section{Differential impacts}

Changes in the geophysical system at various levels of forcing have been routinely explored by the geoscience community. However, so far little emphasis has been given to the quantification of differential impacts at specific levels of warming, such as $1.5^{\circ} \mathrm{C}, 2{ }^{\circ} \mathrm{C}$ and higher levels. Indeed, it is startling that although basically all scenarios that have been run with complex Earth system models cross the $1.5^{\circ} \mathrm{C}$ threshold at some point, a systematic overview of impacts at that level was not provided in earlier assessments. Not all geophysical impacts scale in lockstep with temperature ${ }^{11}$. Impacts in the transient state might differ from those closer to equilibrium, and some impacts like extreme events might require large ensembles to obtain a sufficient signal-to-noise ratio (Fig. 1). Developing methods and conducting dedicated analyses to quantify these differences in a more structured way at various levels of warming that are often not more than half a degree apart is essential to generate the inputs that feed into continuous risk assessments, and to better understand the requirements for adaptation.

\section{Estimating the unavoidable}

The Paris Agreement recognizes "the importance of averting, minimizing and addressing loss and damage associated with the adverse effects of climate change". At the same time, it was decided as part of the deal forged in Paris that any future improved understanding of loss and damage would not involve or provide a basis for liability or compensation. Despite this political decision, understanding and quantifying the extent of future physical changes under climate change remains a priority. The Paris Agreement indicates directions in which the understanding of such adverse effects of climate change should be enhanced.

New directions could include research related to climate services like early warning systems, emergency preparedness, slow onset events like sea-level rise, events that may involve irreversible and permanent loss and damage, and comprehensive risk assessment and management. Continued efforts to develop seamless prediction systems for weather and climate thus remain high on the agenda.

Our society will also need estimates of what is unavoidable. Climate impact estimates in the next 10 to 20 years are very much dominated by our understanding of internal variability (Fig. 1a) and potential abrupt mitigation of short-lived climate forcers. In the long term, however, it is our understanding of the forced response of the Earth system to atmospheric greenhouse gas concentrations, land use or other changes that will determine our assessment of which impacts are deemed unavoidable, even under a climatic future which is consistent with the Paris Agreement's $2{ }^{\circ} \mathrm{C}$ and $1.5^{\circ} \mathrm{C}$ objectives.

\section{Explore and embrace uncertainty}

Although the Paris Agreement constitutes a milestone in our global response to the threat of climate change, at this point it merely constitutes a plan. Soaring towards $4{ }^{\circ} \mathrm{C}$ and beyond rather than staying well below $2{ }^{\circ} \mathrm{C}$ is still a real possibility, if we fail to act according to the plan. Even when following the plan, climate change might still be larger than expected if significant climate 
or carbon cycle feedbacks, such as clouds or permafrost, turn out to be on the high side. The climate change problem remains loaded with uncertainties: observations are incomplete and may be biased, models do not represent all processes, some processes are still poorly understood and the skill in making seasonal to decadal predictions in most regions is low.

From a perspective of risk, a better quantification of uncertainties, for example those associated with weather extremes, tipping points or the interaction of unexpectedly large local climate change with ecosystems, should remain part of any research agenda. Ultimately, this will allow us to assess the climatic benefits of the climate change mitigation engraved in the Paris Agreement, relative to the full spectrum of potential risks in a world in absence of climate policy. By exploring and embracing uncertainty rather than ignoring it, we can contribute to developing a more resilient society and solutions that are robust under a wide range of potential future scenarios.

\section{Cross-disciplinary collaboration}

The questions and challenges arising from the Paris Agreement are manifold, and many of them stretch far beyond the field of geosciences. Indeed, in order to inform the policy debate in the future, the geosciences will have to continue to reach out to other communities, for example the social sciences, and provide a solid ground for impact and mitigation analyses.

It is only once science provides a clear physical quantification of climate change at 1.5 or $2{ }^{\circ} \mathrm{C}$ global warming that impact analyses can connect these insights to assessments of local exposure and vulnerability. At the same time, in the absence of robust up-to-date quantifications of the Earth system's sensitivity to increasing and decreasing $\mathrm{CO}_{2}$ emissions, climate change mitigation researchers cannot provide reliable future scenarios in line with the Paris Agreement because their analyses almost exclusively focus on radiative forcing or emissions budgets. The geosciences remain a key piece of this puzzle, and to maximize the relevance for the Paris Agreement they need to collaborate further with other disciplines to provide timely and integrated information that can result in a real portfolio of solutions and responses in the face of climate change.

\section{A continued dialogue}

Many question whether the voice of science is actually heard by policy. The First Assessment Report (FAR) by the Intergovernmental Panel on Climate Change (IPCC) pointed out in 1990 that human activities would warm our planet, and since then, $\mathrm{CO}_{2}$ emissions have still been on the rise. The process leading up to the Paris Agreement very much shows that science did not lose its voice. In the socalled structured expert dialogue, which ran over the past two years, the latest scientific knowledge was presented to delegates at the UNFCCC, fostering a dialogue between scientific experts and policymakers. These interactions were summarized ${ }^{12}$ and were highly influential in educating policymakers.

This conversation with scientists has further increased the appetite of policymakers to be informed by the best science, and in one of the decisions that came out of the Paris conference, the research community is encouraged to address information and research gaps related to a warming of $1.5^{\circ} \mathrm{C}$ and the range of impacts at the regional and local scales associated with those scenarios.
The IPCC has been invited to produce a special report by 2018 on impacts and pathways related to the $1.5^{\circ} \mathrm{C}$ target, an endeavour which will need new and topical research to come out in the coming two years. The Paris Agreement thus challenges the research community with important questions that must be addressed in a timely fashion to inform policy. We as geoscientists must take up this challenge and help find solutions to the climate change threat that are viable both in the next decade and over the course of this century.

Joeri Rogelj is at the International Institute for Applied Systems Analysis, Schlossplatz 1, 2361 Laxenburg, Austria. Reto Knutti is at ETH Zurich, Universitätstrasse 16, 8092 Zurich, Switzerland.

e-mail:rogelj@iiasa.ac.at

References

1. Adoption of the Paris Agreement $\mathrm{FCCC} / \mathrm{CP} / 2015 / \mathrm{L} .9 /$ Rev.1 (UNFCCC, 2015).

2. United Nations Framework Convention on Climate Change FCCC/INFORMAL/84 (UNFCCC, 1992).

3. Rogelj, J. et al. Nature Clim. Change 5, 519-527 (2015).

4. Collins, M. et al. in Climate Change 2013: The Physical Science Basis (eds Stocker, T. F. et al.) 1029-1136 (Cambridge Univ. Press, 2013).

5. Obersteiner, M. et al. Science 294, 786-787 (2001).

6. Smith, P. et al. Nature Clim. Change 6, 42-50 (2016).

7. Scott, V., Haszeldine, R. S., Tett, S. F. B. \& Oschlies, A. Nature Clim. Change 5, 419-423 (2015).

8. Matthews, H. D. \& Caldeira, K. Geophys. Res. Lett. 35, L04705 (2008)

9. Knutti, R. \& Rogelj, J. Climatic Change 133, 361-373 (2015)

10. Myhre, G. et al. in Climate Change 2013: The Physical Science Basis (eds Stocker, T. F. et al.) 659-740 (Cambridge Univ. Press, 2013).

11. Knutti, R., Rogelj, J., Sedláček, J., Fischer, E. M. Nature Geosci. 9, 13-18 (2016)

12. Report on the structured expert dialogue on the 2013-2015 review FCCC/SB/2015/INF.1 (UNFCCC, 2015).

13. Rogelj, J., McCollum, D. L., O’Neill, B. C. \& Riahi, K. Nature Clim. Change 3, 405-412 (2013).

14. Hurrell, J. W. et al. Bull. Am. Meteorol. Soc. 94, 1339-1360 (2013).

Published online: 22 February 2016 